\title{
Should we use a simple or complex model for moisture recycling and atmospheric moisture tracking?
}

\author{
R. J. van der Ent ${ }^{1}$, O. A. Tuinenburg, ${ }^{2, *}$, H.-R. Knoche ${ }^{3}$, H. Kunstmann ${ }^{3,4}$, and H. H. G. Savenije ${ }^{1}$ \\ ${ }^{1}$ Department of Water Management, Faculty of Civil Engineering and Geosciences, Delft University of Technology, \\ P.O. Box 5048, 2600GA Delft, the Netherlands \\ ${ }^{2}$ Earth System Science and Climate Change Group, Wageningen University and Research Centre, P.O. Box 9101, \\ 6700HB Wageningen, the Netherlands \\ ${ }^{3}$ Interaction Climate-Atmosphere Department, Institute for Meteorology and Climate Research - Atmospheric Environmental \\ Research (IMK-IFU), Karlsruhe Institute of Technology (KIT), Kreuzeckbahnstraße 19, \\ 82467 Garmisch-Partenkirchen, Germany \\ ${ }^{4}$ Department of Geography, Augsburg University, Universitätsstraße 10, 86159 Augsburg, Germany \\ *now at: Laboratoire de Météorologie Dynamique, IPSL/CNRS/UPMC, 4, place Jussieu, 75252 Paris Cedex 05, France
}

Correspondence to: R. J. van der Ent (r.j.vanderent @ tudelft.nl)

Received: 1 May 2013 - Published in Hydrol. Earth Syst. Sci. Discuss.: 29 May 2013

Revised: 29 October 2013 - Accepted: 7 November 2013 - Published: 6 December 2013

\begin{abstract}
This paper compares state-of-the-art atmospheric moisture tracking models. Such models are typically used to study the water component of coupled land and atmosphere models, in particular quantifying moisture recycling and the source-sink relations between evaporation and precipitation. There are several atmospheric moisture tracking methods in use. However, depending on the level of aggregation, the assumptions made and the level of detail, the performance of these methods may differ substantially. In this paper, we compare three methods. The RCM-tag method uses highly accurate 3-D water tracking (including phase transitions) directly within a regional climate model (online), while the other two methods (WAM and 3D-T) use a posteriori (offline) water vapour tracking. The original version of WAM is a single-layer model, while 3D-T is a multi-layer model, but both make use the "well-mixed" assumption for evaporation and precipitation. The a posteriori models are faster and more flexible, but less accurate than online moisture tracking with RCM-tag. In order to evaluate the accuracy of the a posteriori models, we tagged evaporated water from Lake Volta in West Africa and traced it to where it precipitates. It is found that the strong wind shear in West Africa is the main cause of errors in the a posteriori models. The number of vertical layers and the initial release height of tagged water in the model are found to have the most significant influences on the results.
\end{abstract}

With this knowledge small improvements have been made to the a posteriori models. It appeared that expanding WAM to a 2-layer model, or a lower release height in 3D-T, led to significantly better results. Finally, we introduced a simple metric to assess wind shear globally and give recommendations about when to use which model. The "best" method, however, very much depends on the research question, the spatial extent under investigation, as well as the available computational power.

\section{Introduction}

Studying where the rain comes from is of growing interest in the scientific community. In the beginning of the second half of the twentieth century several pioneer researchers were addressing this question (e.g. Benton, 1949; McDonald, 1962; Budyko, 1974; Molion, 1975). Many studies thereafter used simple bulk methods or conceptualizations of the hydrological cycle in order to estimate the amount of precipitation that recycled within a certain region (e.g. Lettau et al., 1979; Brubaker et al., 1993; Eltahir and Bras, 1996; Schär et al., 1999; Trenberth, 1999). The results obtained were, however, only a rough estimate over a large region and subject to several assumptions (Burde and Zangvil, 2001a, b; Fitzmaurice, 
2007). Other studies focused on finding the recycling along a streamline (Savenije, 1995a, b; Lintner et al., 2013; Schaefli et al., 2012), which added to the conceptual understanding of moisture feedback, but has not yet proven to provide reliable estimates in real-world cases. A completely different approach, namely the use of stable isotopes of water: $\delta^{2} \mathrm{H}$, $\delta^{18} \mathrm{O}$ and the corresponding $\mathrm{d}$-excess value, has been shown to be a good indicator for moisture recycling and moisture recycling variability (e.g. Salati et al., 1979; Njitchoua et al., 1999; Henderson-Sellers et al., 2002; Pang et al., 2004; Tian et al., 2007; Froehlich et al., 2008; Liu et al., 2008; Risi et al., 2013). However, good temporal and spatially consistent isotope records are generally not available, and additional meteorological observations are needed to pinpoint the origin of the water more accurately.

There also exist many studies that numerically track moisture (we use the term moisture in this paper for all possible phases of water) in the atmosphere. The first studies, to our knowledge, that can be characterized as atmospheric moisture tracking studies were those of Joussaume et al. (1986) and Koster et al. (1986). The latter used a water vapour tracing scheme in a coarse resolution GCM (general circulation model) to estimate the origin of precipitation in several regions. In contrast to most bulk methods, atmospheric moisture tracking can determine the spatio-temporal distribution of moisture origin rather than merely the recycling rate over a large temporal and spatial scale.

The majority of all recent studies addressing the origin of precipitation, or fate of evaporation, use some sort of atmospheric moisture tracking model. Moisture tracking can be done either parallel (online) to a climate or weather model run (e.g. Bosilovich and Schubert, 2002; Bosilovich and Chern, 2006; Sodemann et al., 2009; Goessling and Reick, 2013; Knoche and Kunstmann, 2013) or a posteriori (offline) with reanalysis data (e.g. Yoshimura et al., 2004; Dominguez et al., 2006; Dirmeyer and Brubaker, 2007; Bisselink and Dolman, 2008; van der Ent et al., 2010; Tuinenburg et al., 2012), operational analysis data (e.g. Stohl and James, 2005; Nieto et al., 2006; Sodemann et al., 2008; Gimeno et al., 2010; Spracklen et al., 2012) or output of a climate model run (e.g. Gangoiti et al., 2011; Goessling and Reick, 2011). Besides using different types of input, these models use significantly different moisture tracking methods (see Gimeno et al., 2012; van der Ent, 2012).

To date, consistent comparison studies of the state-ofthe-art moisture tracking models are rare and the consequences of the different assumptions made are largely unknown. Noteworthy is, however, the study of Goessling and Reick (2013), who compared continental precipitation recycling ratios and moisture origins obtained by using 2-D and 3-D water vapour tracers within the ECHAM6 GCM. They concluded that in general the 2-D approximation is less appropriate in the tropics where it leads to substantial errors. Our paper is to a certain extent similar to the approach of Goessling and Reick, but here we focus on the more widely applied a posteriori models. Our aim is to (1) identify the different characteristics of atmospheric moisture tracking models, (2) quantify the differences in a particular case study, which is in West Africa, where we track water from Lake Volta during a monsoon period with a complex atmospheric flow, providing a challenging task for our models, (3) explain these differences, (4) improve on existing a posteriori models, and (5) translate our findings into recommendations for future atmospheric moisture tracking studies.

Although atmospheric moisture tracking as a research field is partly driven by pure curiosity, already in the past researchers considered the results important for land and water management (e.g. Molion, 1975; Lettau et al., 1979; Savenije, 1995a, b) and also more recent studies generally underline the management implications of their results (e.g. Kunstmann and Jung, 2007; Dominguez and Kumar, 2008; Hossain et al., 2009; Jódar et al., 2010; Goessling and Reick, 2011; Bagley et al., 2012; Keys et al., 2012; Tuinenburg et al., 2012; van der Ent et al., 2012; Wei et al., 2012). In order to use the results of moisture tracking studies for land and water management practices, it is important to better understand the effect that the use of different models may have on the outcome.

\section{Model characteristics}

\subsection{General principles}

The basic equation for all atmospheric moisture tracking models is the balance of a water mass $S(t, x, y, z)$, of which a certain part is tagged $S_{g}$ :

$$
\frac{\partial S_{g}}{\partial t}=\frac{\partial\left(S_{g} u\right)}{\partial x}+\frac{\partial\left(S_{g} v\right)}{\partial y}+\frac{\partial\left(S_{g} w\right)}{\partial z}+E_{g}-P_{g}+\alpha_{g},
$$

where $g$ stands for the source area from which water gets tagged; $t$ is time, $u ; v$ and $w$ are the wind components in the $x, y$ and $z$ direction (note: they can change sign); $E$ is surface evaporation; $P$ is surface precipitation; and $\alpha$ is a residual. Most models only consider water vapour, i.e. $S=S_{\text {vapour }}$, and neglect the liquid and ice water content in an atmospheric column. Moreover, several models only consider horizontal transport (i.e. $\frac{\partial\left(S_{g} w\right)}{\partial z}=0$ ). The vertical resolution in the tracking models ranges from only one layer to tens of layers.

For forward tracking of evaporation, it holds that $E_{g}=E$ if the considered water mass $S$ is above the source region $g$, whereas $E_{g}=0$ elsewhere. Let $E_{g, k}$ be the amount of tagged evaporated moisture which is added to a certain layer in a moisture tracking model, then, the "well-mixed" assumption for the distribution of surface evaporation is described by

$E_{g, k}=E_{g, \mathrm{t}} \frac{S_{k}}{S_{\mathrm{t}}}$,

where $E_{g, t}$ is the total tagged evaporation, $S_{k}$ the water mass in layer $k$ and $S_{\mathrm{t}}$ the total water mass over all layers. In reality, 
surface evaporation enters the atmosphere at the surface, but in a posteriori moisture tracking models it can be desirable to add the water to higher levels as well by using, for example, Eq. (2). The reason for applying such a mixing assumption is that the vertical transport of tagged moisture cannot simply be described by the product of $S_{g}$ and the vertical velocity $w$ given by the input data, because vertical velocity is actually described by

$w=\bar{w}+w^{\prime}$,

where $w^{\prime}$ stands for perturbations from its temporal average. Most a posteriori moisture tracking models neglect these perturbations and assume these are small compared to the variability of the mean vertical wind velocity at the timeresolution of the input data. For input data with fine temporal resolution, this assumption may be valid. However, for input data with coarser temporal resolution, the perturbations could be of significant importance for the tagged moisture transport. A similar argument goes for the spatial resolution. For input data with a fine resolution, the atmospheric vertical transport was resolved in the forcing model. However, for a coarser spatial resolution the actual variability in the moisture transport is not captured by $\overline{S_{g}} \bar{w}$. For these reasons some kind of initial vertical mixing of evaporated moisture could be desired for a posteriori models. Unfortunately, detailed investigations of the resolutions at which an initial vertical mixing as in Eq. (2) would be appropriate have, to our knowledge, not yet been reported in literature.

Likewise, surface precipitation is in reality only present at the surface, but in practice most moisture tracking models do not resolve vertical moisture exchange due to (reevaporating) falling precipitation. For modelling purposes, precipitation from a certain layer $P_{k}$ is therefore considered to be the condensed water that reaches the surface by the precipitation process. Since there is often no information available on the layers from which precipitation falls it is generally assumed that the precipitation is "well-mixed" (i.e. moisture weighted from all model layers):

$P_{k}=P_{\mathrm{t}} \frac{S_{k}}{S_{\mathrm{t}}}$,

where $P_{\mathrm{t}}$ is total precipitation. The tagged fraction of precipitation from a certain layer $P_{g, k}$ is proportional to the tagged moisture fraction at that location:

$P_{g, k}=P_{k} \frac{S_{g, k}}{S_{k}}$.

Similarly to Eq. (5) the tagged horizontal moisture transport terms are assumed to advect water proportional to the tagged moisture fraction at that location:

$\frac{S_{g, k} u}{S_{k} u}=\frac{S_{g, k} v}{S_{k} v}=\frac{S_{g, k} w}{S_{k} w}=\frac{S_{g, k}}{S_{k}}$.

This calculation of tagged moisture $S_{g, k}$ becomes less realistic with less model layers. Some studies have shown that "well-mixed" conditions of tagged atmospheric moisture are usually not met (Bosilovich, 2002; Goessling and Reick, 2013), thus an insufficient number of model layers and the well-mixed assumptions are likely to yield errors.

Furthermore, there is the residual $\alpha$ in Eq. (1), which can be caused by inconsistencies in the input: due to data-assimilation in reanalysis data, resolution upscaling, or model errors, for example, due to interpolation, neglect of liquid water and ice, or the well-mixed assumptions. In order to close the (tagged) water balance, some Eulerian models (implicitly) assign a tagged value to the residual by, for example,considering the residual as a part of the precipitation (e.g. Goessling and Reick, 2011), or by assuming that the residual water behaves similar to a surface flux, with its tagged part being proportional to the tagged moisture in the atmospheric column: $\alpha_{g}=\alpha \frac{S_{g, \mathrm{t}}}{S_{\mathrm{t}}}$ (e.g. Yoshimura et al., 2004).

Lagrangian models generally do not consider the nonclosure of the water balance, but theoretically it is possible to build it in. Also, models differ in the numerical scheme they use to solve Eq. (1). Finally, it should be noted that most models can also perform backward tracking in time (e.g. Dirmeyer and Brubaker, 1999; Stohl et al., 2005; van den Hurk and van Meijgaard, 2009; Keys et al., 2012), making precipitation the source term and evaporation the sink term, with the exception of tracking models that run in parallel with a climate model, which do not allow for backtracking.

Besides uncertainties in the input data, which are independent from the tracking model used, we think that the main sources of error in a posteriori forward tracking models are (a) insufficient number of vertical layers (affecting Eq. 6), (b) the moisture weighted well-mixed assumption when distributing evaporated moisture parcels over the vertical (Eq. 2), (c) the well-mixed assumption for precipitation (Eq. 4), and (d) the neglect of liquid water and ice. Note that a backtracking case would reverse simplifications (b) and (c).

\subsection{Tracking models used in this study}

In this study, we will look into the four error sources listed above by considering three different atmospheric moisture tracking models with three degrees of complexity (Table 1). The most complex method considered is the online tracking model RCM-tag, which runs in parallel to the regional climate model (RCM) MM5. The simplest model (WAM) and the model of intermediate complexity (3D-T) are a posteriori water vapour tracking models, which means that they make use of input provided by climate models, reanalysis, gridded observed products or a combination thereof and consider water vapour only. A detailed description of these models is given below. 
Table 1. Characteristics of the tracking methods. $q$ is specific humidity, $u$ is zonal wind speed, $v$ is meridional wind speed, $w$ is vertical wind speed, $P$ is precipitation and $E$ is evaporation. In case the input data is given on pressure levels instead of model levels then surface pressure is required as well for WAM and 3D-T. For more information on the methods: RCM-tag (Knoche and Kunstmann, 2013), WAM (van der Ent et al., 2010; van der Ent and Savenije, 2011; Keys et al., 2012), and 3D-T (Tuinenburg et al., 2012).

\begin{tabular}{|c|c|c|c|c|c|c|c|c|}
\hline Method & $\begin{array}{l}\text { Input data } \\
\text { needed }\end{array}$ & $\begin{array}{l}\text { Traced } \\
\text { water }\end{array}$ & $\begin{array}{l}\text { Flux } \\
\text { treatment }\end{array}$ & $\begin{array}{l}\text { Model } \\
\text { coordinate } \\
\text { system }\end{array}$ & $\begin{array}{l}\text { Numerical } \\
\text { considerations }\end{array}$ & $\begin{array}{l}\text { Computation } \\
\text { speed }\end{array}$ & $\begin{array}{l}\text { Speed } \\
\text { dependency }\end{array}$ & $\begin{array}{l}\text { Backward } \\
\text { tracking in } \\
\text { time possible? }\end{array}$ \\
\hline RCM-tag & $\begin{array}{l}\text { Boundary } \\
\text { conditions } \\
\text { for the } \\
\text { climate } \\
\text { model }\end{array}$ & All & $\begin{array}{l}\text { Transport } \\
\text { as well as } \\
\text { phase } \\
\text { transitions } \\
\text { at full } \\
\text { model } \\
\text { resolution }\end{array}$ & $\begin{array}{l}\text { Eulerian } \\
\text { tracking }\end{array}$ & $\begin{array}{l}\text { Leap-frog } \\
\text { scheme: } \\
\text { Courant } \\
\text { criterion, } \\
\text { numerical } \\
\text { dispersion }\end{array}$ & Slow & $\begin{array}{l}\text { Linear } \\
\text { proportional } \\
\text { to the } \\
(t, x, y, z) \text { - } \\
\text { model domain }\end{array}$ & $\begin{array}{l}\text { No, forward } \\
\text { only }\end{array}$ \\
\hline $\begin{array}{l}\text { WAM } \\
\text { (1layer) }\end{array}$ & $\begin{array}{l}q(t, x, y, z)^{1} \\
u(t, x, y, z)^{1} \\
v(t, x, y, z)^{1} \\
E(t, x, y) \\
P(t, x, y)\end{array}$ & $\begin{array}{l}\text { Water } \\
\text { vapour } \\
\text { only }\end{array}$ & $\begin{array}{l}\text { Vertically } \\
\text { integrated } \\
\text { fluxes. } \\
\text { 'Well-mixed' } \\
\text { assumption } \\
\text { for } \\
E \text { and } P^{3}\end{array}$ & $\begin{array}{l}\text { Eulerian } \\
\text { tracking } \\
\text { on model } \\
\text { coordinates }\end{array}$ & $\begin{array}{l}\text { Explicit } \\
\text { scheme: } \\
\text { Courant } \\
\text { criterion, } \\
\text { numerical } \\
\text { dispersion }\end{array}$ & Very fast & $\begin{array}{l}\text { Linear } \\
\text { proportional } \\
\text { to the } \\
(t, x, y) \text { - } \\
\text { model domain }\end{array}$ & Yes \\
\hline $\begin{array}{l}\text { 3D-T } \\
\text { (E_wellmixing- } \\
\text { P_wellmixing) }\end{array}$ & $\begin{array}{l}q(t, x, y, z) \\
u(t, x, y, z) \\
v(t, x, y, z) \\
w(t, x, y, z)^{2} \\
E(t, x, y) \\
P(t, x, y)\end{array}$ & $\begin{array}{l}\text { Water } \\
\text { vapour } \\
\text { only }\end{array}$ & $\begin{array}{l}\text { "Well-mixed" } \\
\text { assumption } \\
\text { for } \\
E \text { and } P^{3}\end{array}$ & $\begin{array}{l}\text { Lagrangian } \\
\text { tracking on } \\
\text { Eulerian } \\
\text { coordinates }\end{array}$ & $\begin{array}{l}\text { Explicit } \\
\text { scheme, but no } \\
\text { numerical } \\
\text { issues due to } \\
\text { the Lagrangian } \\
\text { system }^{4}\end{array}$ & Moderate & $\begin{array}{l}\text { Linear } \\
\text { proportional } \\
\text { to the number } \\
\text { of tracers } \\
\text { released and } \\
\text { thus the size } \\
(t, x, y) \text { - } \\
\text { source area }\end{array}$ & Yes \\
\hline
\end{tabular}

\footnotetext{
${ }^{1}$ In principle the vertically integrated moisture flux and the total column water vapour are sufficient, but these are usually not directly available. ${ }^{2}$ Vertical wind speed is preferably given in $\mathrm{Pa} \mathrm{s}^{-1}$ rather than $\mathrm{m} \mathrm{s}^{-1}$. In the case study, the input data of vertical wind speed was given in $\mathrm{m} \mathrm{s}^{-1}$ and the approximation: $1 \mathrm{hPa}=10 \mathrm{~m}$ was used.

3 The well-mixed assumption (of the vertical atmosphere) implies that precipitation is assumed to be removed weighted with the total moisture from each model layer. In the case of WAM the actual horizontal tracking is performed with only one vertical layer and is thus also "well mixed". ${ }^{4}$ Accuracy of the solution does, however, depend on the tracer density and chosen time step.
}

\subsubsection{RCM-tag}

This highly complex tracking model is described by Knoche and Kunstmann (2013), who built it into MM5. Some key points of the model are also given in Table 1. The general principle is to keep track of the additional to MM5 introduced "tagged" moisture species without affecting MM5's overall water balance. Where most other methods only consider transport of water vapour, RCM-tag considers all atmospheric processes, i.e. transport, horizontal diffusion as well as phase transitions. It should be noted that no subgrid scale cumulus (convection) parameterization is applied with regard to a moisture tagging modelling, because according to Knoche and Kunstmann (2013) a consistent treatment by a cumulus parameterization scheme is difficult to achieve. Instead, model resolutions generally assumed to be fine enough to capture the most important convection systems by gridscale resolved dynamic model processes have to be used. Therefore, the relevant moisture transitions are calculated by an explicit scheme. The tracking by RCM-tag as such can be considered "virtual reality". Accuracy is the main advantage of this method, but on the other hand it is slow in computation and backtracking in time is not possible.

\subsubsection{Water accounting model}

The simplest model used (see Table 1) is the water accounting model (WAM) (van der Ent et al., 2010; van der Ent and Savenije, 2011; Keys et al., 2012), which reduces the tracking to a 2-D $(x, y)$ problem, by computing the vertically integrated moisture fluxes. This means that the water mass $(S)$ is equal to the total column water mass $\left(S_{\mathrm{t}}\right)$ in Eq. (1) and the number of layers $(k)$ in Eqs. (2) and (4) to (6) is 1. WAM runs on an Eulerian grid and can be run in forward as well as backward tracking mode. The model excels in computation speed due to its simplicity, but also due to its Eulerian grid allowing it to track moisture from large source areas just as fast as from small source areas. However, it is expected to be less accurate in studies demanding high spatial and temporal resolution. 
Location of the study domain

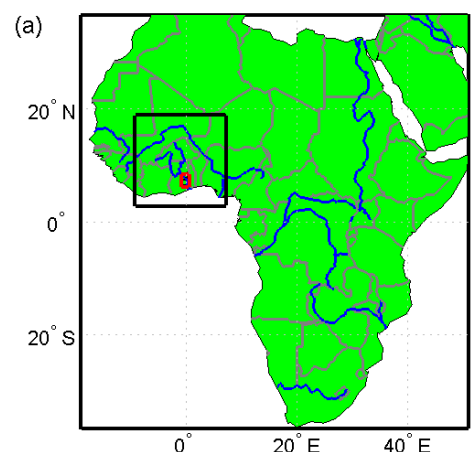

Wind field near the surface

(b)

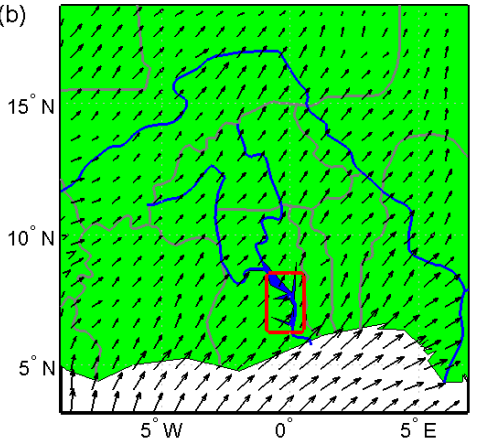

Wind field at approx. $500 \mathrm{hPa}$

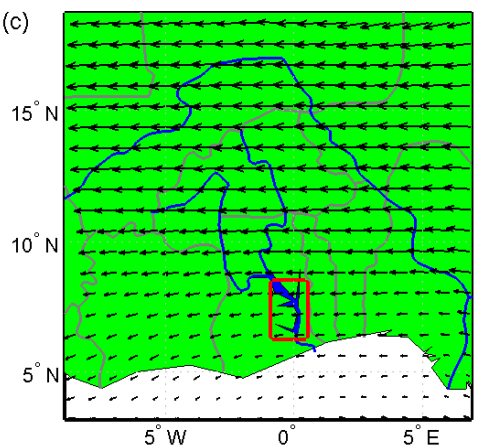

Fig. 1. Study domain and wind fields at different heights (arrows) averaged over August 1998 according to the MM5 model run. (a) location of the study domain (black rectangle) within Africa, (b) the wind field near the surface, and (c) the wind field at a model layer which corresponds to approximately $500 \mathrm{hPa}$ or $5 \mathrm{~km}$. Rivers and Lake Volta are shown in blue, country borders in grey and the tagging source area lies within the red rectangle. Note that in the text the tagging source area is sometimes referred to as Lake Volta, but actually covers some of its surroundings as well.

\subsubsection{D-Trajectories}

The next model considered (see Table 1) is 3D-Trajectories (3D-T) (Tuinenburg et al., 2012), which is a modification of the quasi-isentropic back-trajectory (QIBT) method of Dirmeyer and Brubaker $(1999,2007)$, but in contrast to QIBT, 3D-T does not use potential temperature as a vertical coordinate system. Instead it uses pressure coordinates and the vertical wind speed to calculate the vertical motion of tracked parcels. Water parcels are tracked in a Lagrangian manner and are released into the atmosphere at a random starting height weighted by the moisture profile (Eq. 2). Transport in the atmosphere is based on a linear interpolation of the 3-D wind patterns of the forcing data. It also uses the "well-mixed" assumption for precipitation (Eq. 4). 3D-T can be run in forward as well as backward tracking mode. Computation speed of 3D-T generally lies between WAM and RCM-tag, but is dependent on tagging source area (a larger area requires more tracer parcels) rather than the model domain only in WAM and RCM-tag.

\subsubsection{Modified WAM and 3D-T models}

Based on the results that are shown later in this paper, we have decided to make several changes to WAM and 3D-T in order to try to match the "virtual reality" of RCM-tag better. In WAM we changed from a single to two layers in the vertical. In 3D-T we adjusted the mixing assumptions for evaporation and precipitation. Further description of these changed models is given in Sect. 3.3.

\subsection{Relation to other moisture tracking models}

Most other atmospheric moisture tracking models used (e.g. Bosilovich and Schubert, 2002; Yoshimura et al., 2004; Dominguez et al., 2006; Dirmeyer and Brubaker, 2007;
Gangoiti et al., 2011; Goessling and Reick, 2011) are essentially variations on the three models described in Table 1 (see Gimeno et al., 2012, for a review). Their complexity and (dis)advantages lie somewhere between the models used in this study (Tables 1 and 3).

There are two other widely used and advanced Lagrangian models that are used for atmospheric water tracking: FLEXPART (Stohl et al., 2005) and HYSPLIT (Draxler and Hess, 1998), which are distinctively different from the three discussed models here, since they only consider the net interaction with the surface $(P-E)$, meaning that they cannot diagnose precipitation and evaporation separately. Nonetheless, these methods have been successfully applied in several recent studies (e.g. Nieto et al., 2006; Sodemann et al., 2008; Gimeno et al., 2010; Durkee et al., 2012), and for HYSPLIT there is even a web-based tool for moisture trajectory calculations (Draxler and Rolph, 2013).

\section{Case study Lake Volta (West Africa)}

\subsection{Description}

Our case study consists of comparing the three models (RCM-tag, WAM and 3D-T) for their ability to correctly track evaporation from Lake Volta. The study domain is the same domain that is studied by Knoche and Kunstmann (2013). The domain, that exist of a large part of West Africa (Fig. 1a), is modelled with MM5 (Grell et al., 1995) for two months: July and August 1998, which are in the middle of the monsoon season. The area is relatively flat, and the only noteworthy orographic features are the Togo Mountains (peaks of 300-1000 m), which are situated just east of the tagging source region (red rectangle in Fig. 1). Furthermore, Fig. 1 shows the wind vectors near the surface (i.e. at the lowest model level, Fig. 1b), and the wind vectors at the 

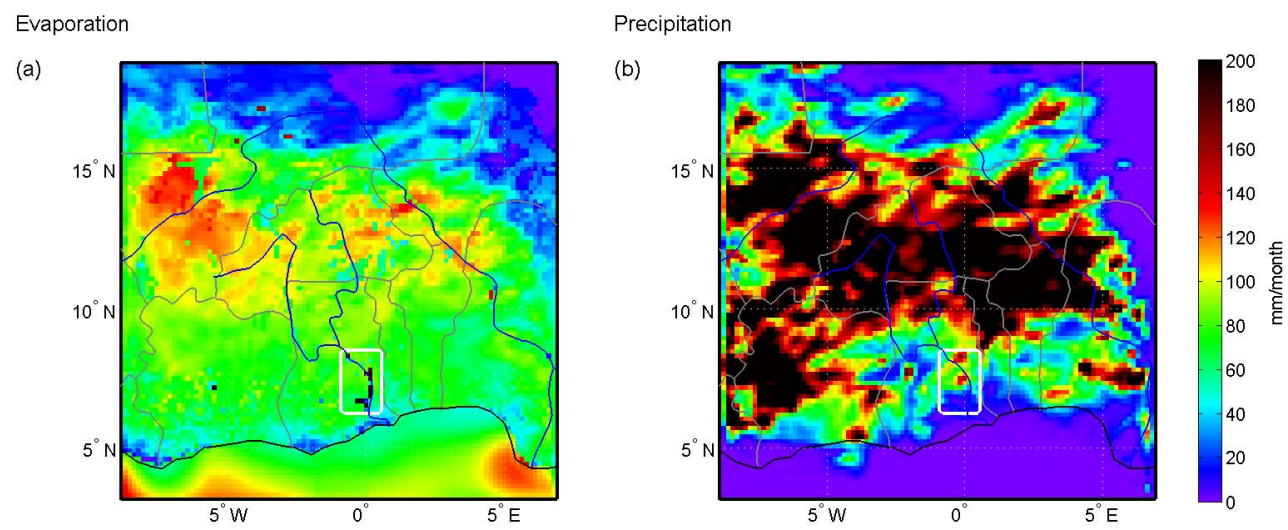

Fig. 2. Vertical fluxes in August 1998 according to the MM5 model run. (a) evaporation, and (b) precipitation. The areal average evaporation of the Lake Volta tagging region is $85 \mathrm{~mm} \mathrm{month}^{-1}$ compared to $67 \mathrm{~mm}$ month $^{-1}$ over the whole domain. The areal average precipitation of the Lake Volta tagging region is $62 \mathrm{~mm} \mathrm{month}^{-1}$ compared to $87 \mathrm{~mm} \mathrm{month}^{-1}$ over the whole domain.

model level which corresponds approximately to $500 \mathrm{hPa}$ or $5 \mathrm{~km}$ a.s.l. (above sea level) (Fig. 1c), for the period of August 1998. The wind near the surface brings in air from the ocean, while at $500 \mathrm{hPa}$ the wind field is nearly geostrophic in westward direction. This system is thus to a high degree a sheared system, of which we found the interface generally to lie at approximately $800 \mathrm{hPa}$ or $2 \mathrm{~km}$ a.s.l. (not shown).

Furthermore, Fig. 2 shows the evaporation and precipitation in the same month. The land evaporation (Fig. 2a) seems highest at the places that receive the most rain (Fig. 2b). Also, the actual Lake Volta grid cells (within the white rectangle) can easily be identified by their high evaporation rates. As can be seen in Fig. 2b, the coastal area experiences a small dry season and the precipitation maxima are found between 10 and $15^{\circ} \mathrm{N}$ where the ITCZ is located (Pidwirny, 2006). Most of this precipitation is convective and believed to have a strong coupling with the soil-moisture (e.g. Koster et al., 2004; van den Hurk and van Meijgaard, 2009; Taylor et al., 2010), which is also evident from short-length scales of local recycling (van der Ent and Savenije, 2011).

With three different models (Table 1), the evaporation from a small area $\left(4 \times 10^{4} \mathrm{~km}^{2}\right)$ including Lake Volta in Ghana (red square, Fig. 1) is tagged, and subsequently traced until it leaves the model domain or precipitates. Thus, all three models run in forward tracking mode. The grid cell size used is $18 \mathrm{~km} \times 18 \mathrm{~km}$ (at the equator), with 33 vertical model layers. The RCM-tag run is performed directly in parallel with MM5; the time step used is $50 \mathrm{~s}$. The two other models use hourly MM5 output data as their input data. In both WAM and 3D-T these data are downscaled to $6 \mathrm{~min}$. The residuals (see Eq. 1) were found to be very small with WAM (not shown), and were not given a tagging component. The results focus on August 1998 only, but with the initial conditions (i.e. tagged water) given by the July run.

\subsection{Results}

This section discusses the results of atmospheric moisture tracking with 3 different models. As RCM-tag includes all the processes that are also present in the normal MM5 scheme, we consider the results from RCM-tag to represent "virtual reality". First, we discuss these results and then we compare the results of the a posteriori moisture tracking methods WAM and 3D-T with the results of RCM-tag. A summary of the results is presented in Table 2. The movies can be found in the Supplement, which also contains an overview of Figs. 3-8 on one page.

\subsubsection{RCM-tag}

In Fig. 3 and movie 1 (Supplement), we can see what happens with the evaporated water from Lake Volta in August 1998. The general pattern is that moisture is first transported by the surface winds (Fig. 1b) to the northeast until it reaches higher levels of the atmosphere, after which it is picked up by the African easterly jet (Cook, 1999), transporting moisture westward (Fig. 1c). But, as the movie clearly shows, this process is variable in time, which seems to be caused by variability in the surface winds. For example, on 19 August it is observed that all tagged water is transported in westerly direction.

Figure 3 shows that evaporation from Lake Volta is most likely to end up as precipitation just north of the source region. In movie 1 (Supplement) we see that the tagged atmospheric moisture also reached areas south of Lake Volta, but that it did not rain out (see Fig. 2b). Only a few spots in the domain receive more than $5 \mathrm{~mm}$ month $^{-1}$ of rain originating from Lake Volta. Compared to the total amount of rainfall (Fig. 2b) the tagged rain accounts only for a few percent. Nonetheless, we can say that evaporation from Lake Volta is a very active component of the regional hydrological cycle as 
Table 2. The amount of evaporation from the Lake Volta region (Fig. 1), which recycles as precipitation within the domain and locally computed with different water tracking models. These results are for August 1998.

\begin{tabular}{lccc}
\hline Tracking model & $\begin{array}{c}\text { Evaporation of Volta origin } \\
\text { that precipitates within the } \\
\text { domain, i.e. domain recycling }\end{array}$ & $\begin{array}{c}\text { Evaporation of Volta origin } \\
\text { that precipitates in the Volta } \\
\text { region, i.e. local recycling }\end{array}$ & $\begin{array}{c}\text { Pattern resembling } \\
\text { that of RCM-tag's } \\
\text { virtual reality }\end{array}$ \\
\hline \multicolumn{3}{c}{ Original models } \\
\hline RCM-tag & $35 \%$ & $1.9 \%$ & Exact \\
WAM (1layer) & $39 \%$ & $2.0 \%$ & Bad \\
3D-T (E_wellmixing- & $12 \%$ & $1.9 \%$ & Reasonable \\
P_wellmixing) & & & Good \\
\hline & $34 \%$ & $2.8 \%$ & Good \\
\hline WAM-2layers & $29 \%$ & $1.8 \%$ & Good \\
3D-T-E_lowmixing- & $34 \%$ & $2.0 \%$ & \\
P_wellmixing & & & \\
3D-T-E_lowmixing- & & & \\
P_fromclouds & & & \\
\hline
\end{tabular}

over one-third of the evaporation recycles within the domain and about $2 \%$ recycles over Lake Volta (see also Table 2).

\subsubsection{Water accounting model}

Figure 4 and movie 2 (Supplement) show that according to WAM the evaporated water from Lake Volta appears to be primarily transported to the west, thus the moisture transport in WAM is apparently dominated by the upper winds (Fig. 1c). The amount of evaporated water from Lake Volta recycling within the domain happens to be almost the same as in RCM-tag (Table 2), but the patterns clearly show that WAM is not a good method to perform such a high-resolution analysis. We attribute the wrong pattern primarily to the fact that WAM uses a single vertical layer, and thus works with a vertically integrated moisture flux, which cannot reproduce the sheared wind system that exists in this region (Fig. 1). In Sect. 3.3.1 we present an update to WAM (WAM2layers), which is much better capable of representing the West African wind system.

\subsubsection{D-Trajectories}

Figure 5 shows that the 3D-T method leads to a downwind tagged precipitation pattern somewhat similar to that of RCM-tag. However, the fraction of evaporation that recycles is a factor three lower than in the RCM-tag simulation (see Table 2). From movie 3 (Supplement) it can clearly be observed that, similar to the WAM run, the 3D-T method partially transports the moisture in the wrong direction. Moreover, in movie 3 (Supplement) tagged water appears to disappear too quickly from the domain in comparison to RCMtag (movie 1, Supplement). This can be attributed to large differences in wind direction and speed between lower and higher atmospheric layers, making the results very sensitive

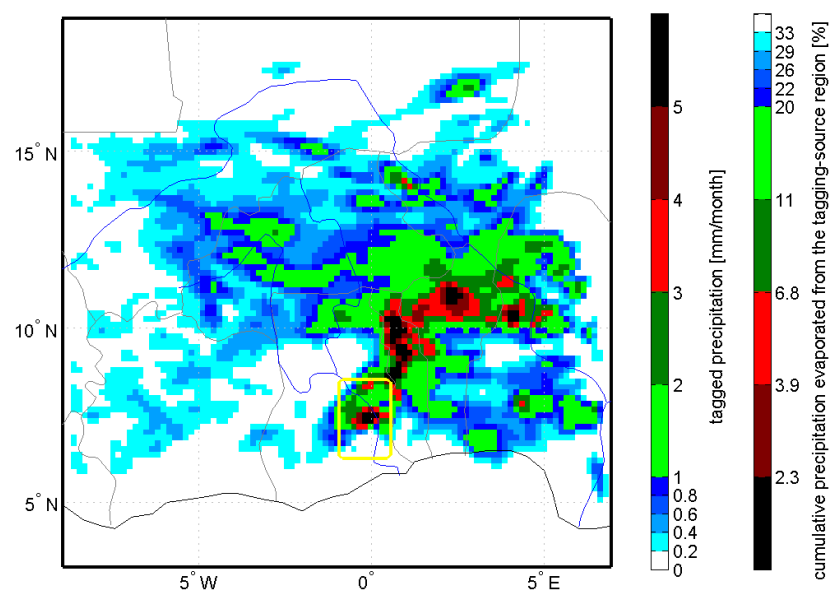

Fig. 3. Precipitation of Volta origin in August 1998 as computed by RCM-tag. The yellow rectangle indicates the Lake Volta taggingsource region. The left colour bar indicates the absolute amount of precipitation that originated from Lake Volta. The right colour bar indicates for which percentage the precipitation in the coloured areas accounts for the evaporation from the tagging-source region. For example, the light green regions receive 1 to $2 \mathrm{~mm} \mathrm{month}^{-1}$ of precipitation that originated from Lake Volta, and in total the tagged precipitation in the light green areas sums up to $20-11=9 \%$ of Lake Volta's evaporation.

to the height at which moisture parcels are released. The spatial and temporal resolution of this case study is apparently too high for the moisture weighted release in the vertical to be applicable.

Although the parcels released by the 3D-T method are transported vertically with the vertical wind speed, a significant fraction of the parcels is released in the westward flowing (higher) layers, and are transported into areas with 

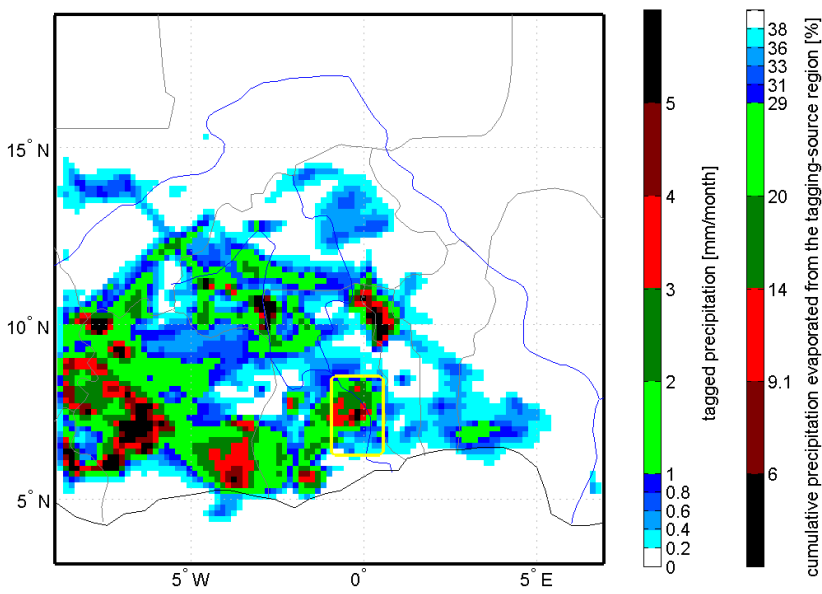

Fig. 4. Precipitation of Volta origin in August 1998 as computed by WAM. See Fig. 3 for an explanation of the colours.

low precipitation and subsequently out of the domain. The parcels that are released in the lower fraction of the atmosphere follow the same pattern as the RCM-tag run and produce the same downwind precipitation pattern, however, only about a third of the parcels are released in the eastward flowing layer (approximately below $2 \mathrm{~km}$ a.s.l.). In Sects. 3.3.2 and 3.3.3 we present updates to 3D-T (i.e. the 3D-T-E_lowmixing runs), which release the evaporated water parcels only in the lowest levels of the atmosphere, which at this high spatial and temporal resolution study offers a better representation of the true dynamics.

\subsection{Simple improvements to the a posteriori moisture tracking methods}

\subsubsection{WAM with 2 layers in the vertical}

It was observed in Sect 3.2.2. that the WAM model provides good recycling quantities (Table 2), but not for the right reasons as too much of the moisture transport is westward (Fig. 4 and movie 2, Supplement). A simple improvement that yielded much better results is splitting the atmosphere into two layers (WAM-2layers). Prior investigation into the vertical distribution of wind velocities showed that the shearlayer is approximately at the sigma level (model level relative to surface pressure) which corresponds roughly to $800 \mathrm{hPa}$ ( $2 \mathrm{~km}$ a.s.l.). Horizontal moisture fluxes in the bottom layer were computed between the surface and that sigma level, while the horizontal moisture fluxes in the top layer were computed between that sigma level and the top of the atmosphere. Moreover, we used the vertical velocity given at the sigma level of around $800 \mathrm{hPa}$ to calculate the moisture transport between the bottom and top layer. At an input time step of $1 \mathrm{~h}$ and a spatial resolution of $18 \mathrm{~km}$, this is an acceptable assumption.

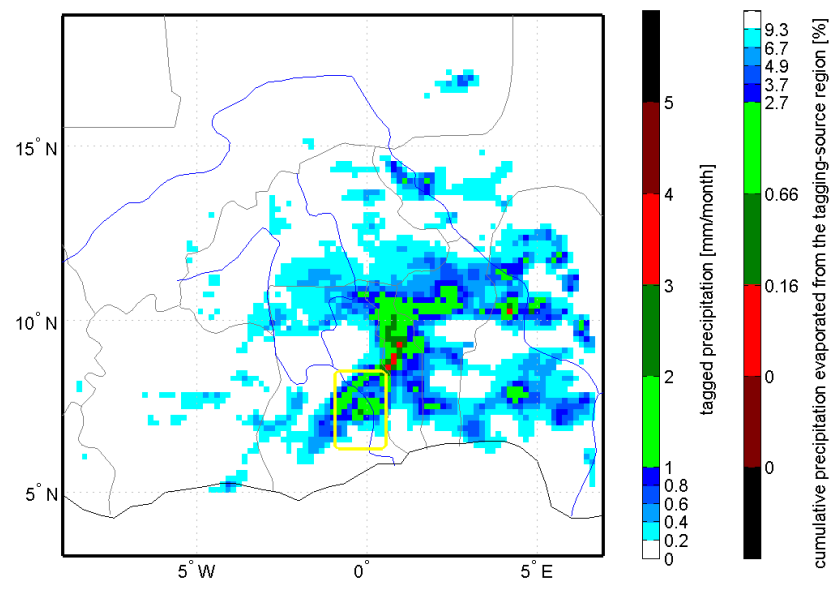

Fig. 5. Precipitation of Volta origin in August 1998 as computed by 3D-T. See Fig. 3 for an explanation of the colours.

Figure 6 and movie 4 (Supplement) show the results for the WAM-2layers run. It can be observed that this run compares very well with RCM-tag (Fig. 3 and movie 1, Supplement). The tagged moisture flowing around the domain, the precipitation pattern, as well as the magnitude of recycling within the domain are nearly identical. A relatively large error is, however, made for the regional recycling ratio within the Lake Volta area: $2.8 \%$ for WAM-2layers vs. $1.9 \%$ with RCM-tag. Yet, over the full model domain this issue is apparently not significant (see also Table 2 ).

\subsubsection{D-T without the well-mixed assumption for evaporation}

One of the most important assumptions of the original 3D$\mathrm{T}$ method is the "well mixed" assumption for the height at which tracer parcels are released in the atmosphere (Eq. 2). The validity of this assumption is related to the vertical mixing that takes place within a single time step. With a large time step this assumption could be valid, but we saw in Sect. 3.2.3 that it did not yield good results in the domain of the current study, especially since the region also has large wind shear. To quantify the effects of this assumption, the 3D-T method was modified (3D-T-E_lowmixing-P_wellmixing in Table 2) and parcels were released from just (50 $\mathrm{m})$ above the land surface.

Figure 7 and movie 5 (Supplement) show the results of this modified run. The patterns have not changed much compared to the original 3D-T run. However, the amount of tagged precipitation in the domain has increased significantly coming much closer to the value of RCM-Tag. The pattern in Fig. 7 resembles the RCM-tag output quite well. It also shows that the tagged precipitation patterns from 3D-T are less smooth compared to RCM-tag and WAM(-2layers). In these latter models, the moisture is transported on an Eulerian grid, which causes some diffusion of the moisture. The 
parcel trajectories in the Lagrangian 3D-T runs do not have this diffusion, so the precipitation is less smooth spatially, which can also be observed in the movies.

\subsubsection{D-T without the well-mixed assumption for evaporation and precipitation}

Apart from the assumption of the height at which the evaporation is released into the atmosphere, discussed in Sect. 3.3.2, the 3D-T method (as well as WAM and WAM2layers) assumes that all moisture in the vertical column contributes equally to precipitation (Eq. 4). To test the sensitivity of this assumption to the precipitation patterns, the precipitation allocation in 3D-T was adapted by using the information about the cloud layers in the RCM-tag run (i.e. the cloud water content in each of the 33 model levels). In this adaptation, precipitation is assumed to originate only from the cloud levels. During the trajectory of the moisture parcels, the amount of precipitation from the parcel during a time step is proportional to the ratio of the cloud fraction from the RCM-tag run at the height of the parcel and the mean cloud fraction over all levels in the column. If no clouds are present at the height of the parcel, the parcel will not contribute to the precipitation.

Figure 8 and movie 6 (Supplement) show the results of this adaptation, together with the release of the parcels from near the land surface. The patterns are similar to that of Fig. 7 and movie 5 (Supplement) and the recycling rates are very close to the RCM-tag run (see also Table 2). Movie 6 (Supplement) clearly shows differences with movie 1 (Supplement) of RCM-tag, which are caused by Lagrangian vs. Eulerian modelling, but from Fig. 8 and Table 2 it can be observed that the results of this run (3D-T-E_lowmixing-P_fromclouds) are closest to the virtual reality.

\subsection{Case study conclusions}

From the prevailing atmospheric conditions present in the West African study area (Fig. 1), especially the wind shear present in the vertical, it was anticipated that the a posteriori water vapour tracking models (WAM and 3D-T) would face difficulties representing the results of the RCM-tag method (Fig. 3). WAM performed particularly bad in getting the direction of the moisture flux right (Fig. 4), but the addition of a second layer yielded results that were quite close to RCM-tag (Fig. 6). The 3D-Trajectories model performed reasonable in reproducing the patterns of RCM-tag (Fig. 5), but failed mainly in getting the recycling ratios right (Table 2). Releasing the parcels near the surface instead of moisture weighted over the vertical significantly improved the results (Fig. 7). Accounting for the presence of clouds instead of using the well-mixed assumption for precipitation improved the results even further (Fig. 8). See the Supplement for Figs. 3-8 on one page.

What can be said about the effects of the major simplifications and possible sources of error in WAM and 3D-T, which

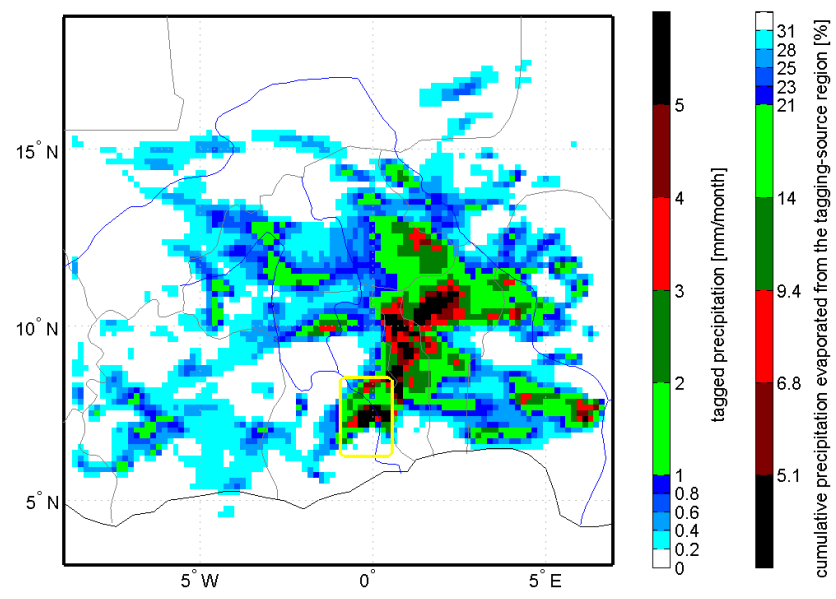

Fig. 6. Precipitation of Volta origin in August 1998 as computed by WAM-2layers. See Fig. 3 for an explanation of the colours.

we identified beforehand? We summarised these as (a) an insufficient number of layers (only one in the original WAM), (b) the moisture weighted well-mixed assumption when distributing evaporated moisture parcels over the vertical, (c) the well-mixed assumption for precipitation, and (d) the neglect of liquid water and ice. In summary, we can say that in this case study assumptions (a) and (b) were found to be the most crucial, and assumptions (c) and (d) of minor importance in obtaining accurate results with the atmospheric moisture tracking models used. A more detailed discussion of these four points is found in the remaining part of this section.

\subsubsection{Insufficient number of layers}

It was found that for this particular case study, the insufficient number of layers was one of the most crucial sources of error in the atmospheric tracking results. The atmospheric moisture tracking model RCM-tag used 33 model-levels. With only one vertical layer WAM was not able to reproduce the pattern of RCM-tag (Fig. 4 and movie 2, Supplement). However, it was not necessary to use all 33 layers as is also done in 3D-T, but splitting the atmosphere in just two well-chosen layers (WAM-2layers) yielded results that were very similar to RCM-tag (see Fig. 6 and movie 4, Supplement).

\subsubsection{Vertical mixing assumption for evaporated parcels}

The tagged evaporated moisture parcels released at a random starting height in 3D-T, weighed by the atmospheric moisture profile (Eq. 2), let to an underestimation of recycling (Sect. 3.2.3). Note that the original WAM run also released its evaporated water over the entire atmospheric profile (as there is only one layer), but the effect of this was not clear as the moisture direction led to larger errors. The new runs: WAM-2layers, 3D-T-E_lowmixing-P_well-mixing and 3DT-E_lowmixing-P_fromclouds, release their tagged moisture near the surface which led to significantly better results 


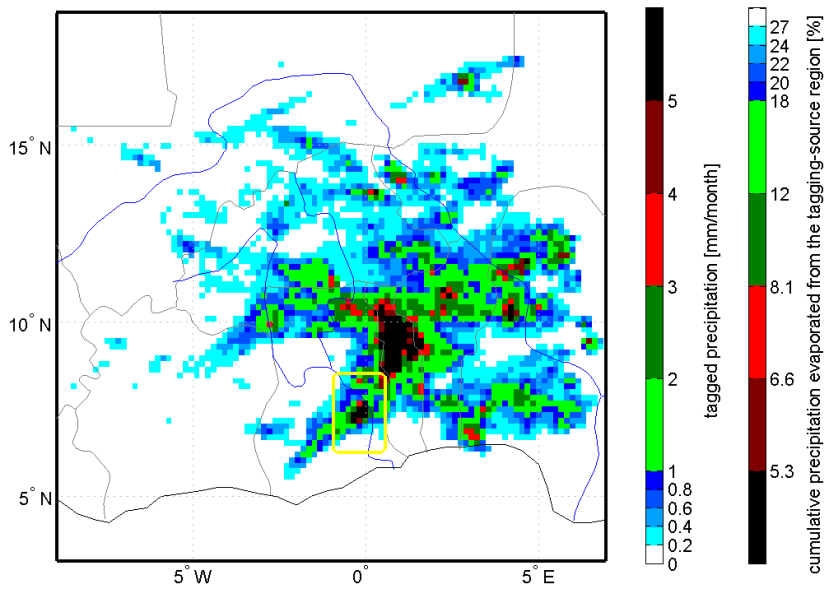

Fig. 7. Precipitation of Volta origin in August 1998 as computed by 3D-T-E_lowmixing. See Fig. 3 for an explanation of the colours.

(Figs. 6-8). Thus, for this high spatial and temporal resolution it appears that it is best to release evaporated parcels near the surface.

To illustrate this, Fig. 9a shows the mean height of parcels released from the source region (Fig. 1) for the different mixing approaches in 3D-T. The mean height of the parcels in the original 3D-T run is higher than in the run with releases from the surface (indicated with "low mixing") during the first $70 \mathrm{~h}$ of the simulation; a $t$ test of the differences between the runs dropped below the $95 \%$ level after $68 \mathrm{~h}$ of simulation. Note that the number of parcels within the domain (on which Fig. 9a is based) decreases in time. As the wind speeds are higher in higher atmospheric layers, the number of parcels present in the original run will be reduced faster than in the "low mixing" run, explaining the fact the black line is higher than the red line after $85 \mathrm{~h}$.

\subsubsection{Vertical mixing assumption for precipitation}

Both atmospheric water vapour tracking methods WAM and 3D-T invoke the so-called "well-mixed" assumption for precipitation (Eq. 4). This means that the precipitation efficiency is assumed the same for all water in the column. From Fig. 9b it can be seen that this is in reality not the case as cloud water has a different vertical distribution than water vapour. In the run 3D-T-E_lowmixing-P_fromclouds (Sect. 3.3.3) we assumed that precipitation can only come from levels where clouds are present. This yielded a small improvement in the magnitude of moisture recycled within the domain (Table 2), but this improvement was much smaller compared to changing the release height of 3D-T (Sect. 3.2.3). Moreover, it was necessary to use additional information about cloud water content from MM5.

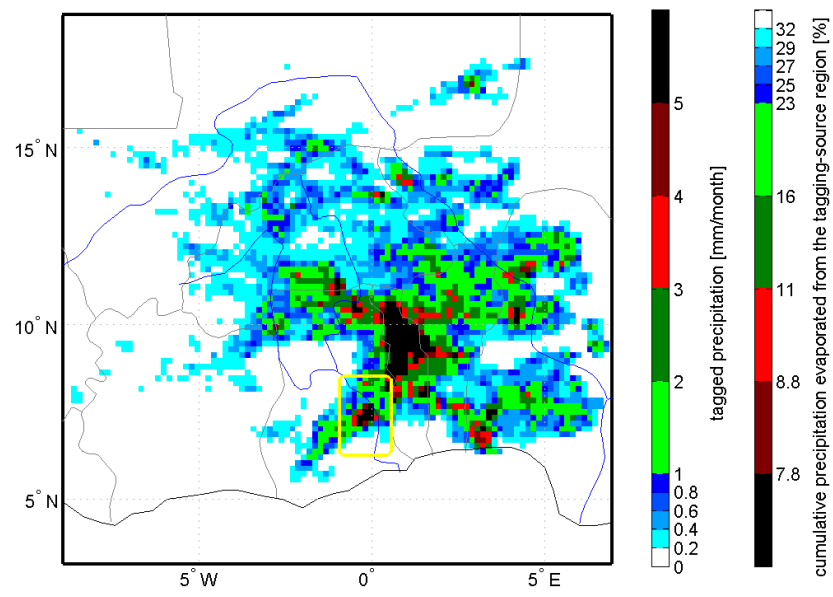

Fig. 8. Precipitation of Volta origin in August 1998 as computed by 3D-T-E_lowmixing-P_fromclouds. See Fig. 3 for an explanation of the colours.

\subsubsection{Neglect of liquid water and ice}

For this case study we can conclude that tracking the water vapour only, and neglecting the presence of liquid water, ice and the corresponding phase transitions in the tracking scheme did not influence the results significantly. We derive this conclusion from our assessment that the improved a posteriori moisture tracking methods WAM-2layers and 3DT-E_lowmixing were both able to reproduce the results of RCM-tag to a satisfying degree of similarity, while assuming all atmospheric water to be water vapour only.

\section{Where is a complex model important?}

In the case study (Sect. 3) we have seen that the wind shear in the West African domain is responsible for the largest errors in the a posteriori tracking models. In single layer WAM this lead to errors in the transport paths predicted by the model, because it used the vertically integrated moisture flux, leading to a net moisture transport in westward direction. This problem was mostly solved in the WAM-2layer run. The 3D$T$ model was affected by the fact that some of the released parcels in the upper atmosphere were going in a different direction than if they had been released closer to the surface. This problem was also solved in the 3D-T-E_lowmixing runs.

It should be noted that we could only make these observations because we had the results from the RCM-tag run available, which generally will not be available beforehand. Therefore, it is desirable to determine the conditions under which it is necessary to run WAM with 2 layers or applying another atmospheric moisture tracking model like 3D$\mathrm{T}$ or RCM-tag. In general we can reason that the larger the tagging source area, the less wind shear is a problem, because tagged water from different parts of the source area will compensate for each other. Nonetheless, to identify in 

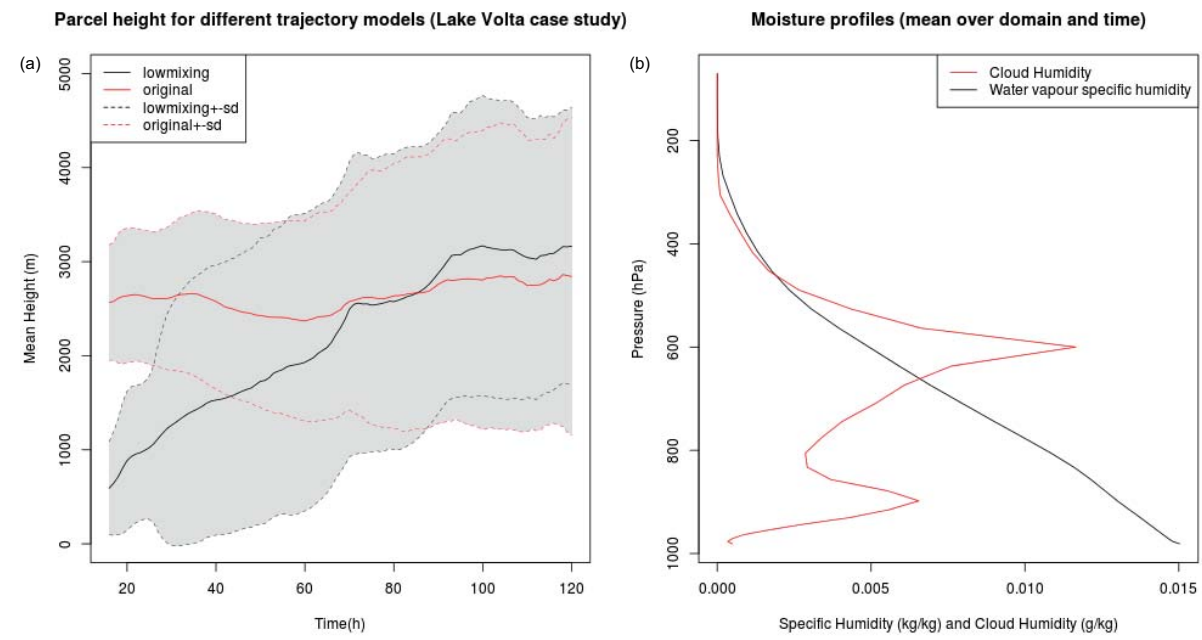

Fig. 9. (a) mean height of parcels in 3D-T for two mixing assumptions for evaporation entering the atmosphere. The red line shows the original assumption in which evaporated moisture is released randomly along the vertical moisture profile (Fig. 5 and movie 3, Supplement). The black line shows the assumption where moisture is released at $50 \mathrm{~m}$ above the land surface. Dotted lines and grey shading shows the range of one standard deviation from the mean height. Both lines are based on a sample size of 1000 parcels. (b) vertical moisture profile (averaged over the domain for August 1998). The red line shows the cloud water content and the black line the specific humidity.

which parts of the world wind shear is a problem for atmospheric moisture tracking, we propose to compute the horizontal moisture flux shear factors:

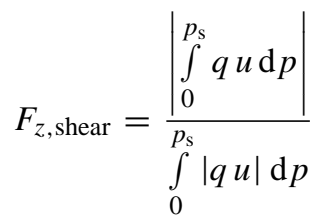

and

$F_{m, \text { shear }}=\frac{\left|\int_{0}^{p_{\mathrm{s}}} q v \mathrm{~d} p\right|}{\int_{0}^{p_{\mathrm{s}}}|q v| \mathrm{d} p}$,

where $q$ is specific humidity, $p$ is pressure and $p_{\mathrm{s}}$ is surface pressure and $u$ and $v$ are zonal and meridional wind speed, which have a positive value in eastward and northward direction, respectively, and a negative sign in the opposite direction. For example, in the extreme case of a completely sheared system, where wind in the lower atmosphere is in eastward direction and wind in the upper atmosphere is in westward direction while the product of $q$ and $u$ is equal for

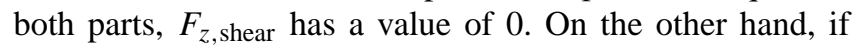
the wind in all layers of the atmosphere is in the same direction, then the system is without shear and $F_{z \text {,shear }}$ has a value of 1 . For clarity, a value of 0.5 means that $75 \%$ of the total horizontal moisture flux goes in one direction and $25 \%$ in opposite direction. These factors can directly be computed from standard climate model output or reanalysis data. A similar metric was proposed by Goessling and Reick (2013).
Figure 10 shows the moisture flux shear factors for the West African case study. It can be observed that shearing is most problematic in the coastal zone, especially for zonal oriented fluxes (Fig. 10a). Shearing is somewhat less problematic in the north of the domain, but cannot be neglected for the moisture tagging from the small Lake Volta area. This confirms the presence of a sheared winds system which was also observable in Fig. 1, and was found to be the main reason of errors in the a posteriori moisture tracking models.

We also applied Eqs. (7) and (8) globally to a $10 \mathrm{yr}$ record of the ERA-Interim reanalysis (60 model levels) (Dee et al., 2011). These results are shown in Fig. 11. Overall, it appears that there is slightly more shearing in the meridional direction (lower numbers in Fig. 11b). Zonal shearing is generally lower and almost non-existent in latitudes above $45^{\circ} \mathrm{N}$. It can be observed from Fig. 11 that the area where one would expect the largest problems for accurate moisture tracking is in fact West Africa. In general most of the problems are expected in Africa and to a lesser extent in South America and Australia. The temperate zones of Eurasia and North America have high horizontal moisture flux shear factors, meaning that the moisture is mostly going in one direction over the whole vertical.

\section{Concluding remarks and recommendations}

In this paper we compared three state-of-the-art atmospheric moisture tracking models that track evaporation until it precipitates (Table 1). We considered the results obtained with the RCM-tag method as "virtual reality". The two other, less complex, methods (WAM and 3D-T) use a posteriori (offline) water vapour tracking. It was found that the original 

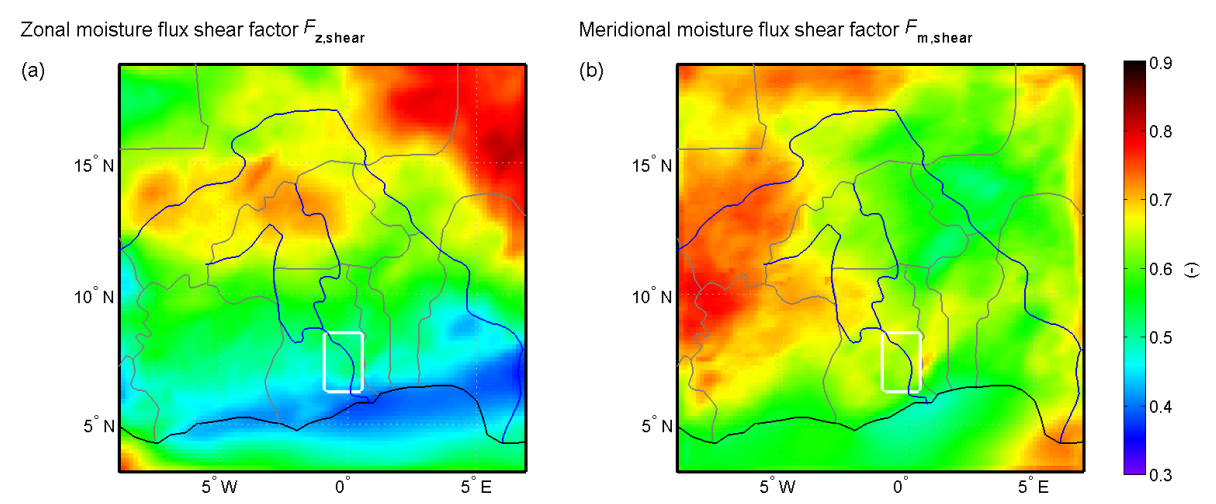

Fig. 10. Horizontal moisture flux shear factors as defined by Eqs. (7) and (8) averaged over August 1998 according to the MM5 model run. (a) Zonal moisture flux shear factor, and (b) meridional moisture flux shear factor. The lower the value the more sheared the moisture flux.

Zonal moisture flux shear factor $F_{z \text { shear }}$

(a)

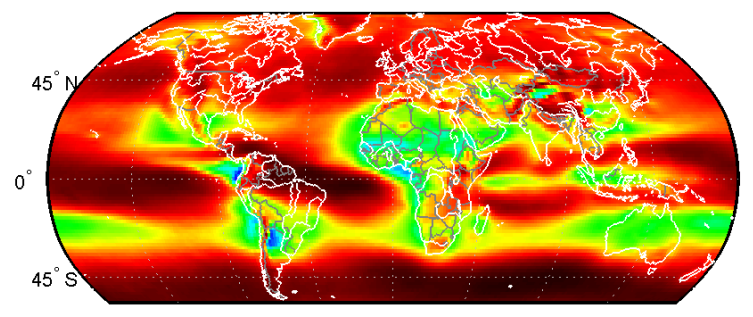

Meridional moisture flux shear factor $F_{\mathrm{m}, \mathrm{shear}}$

(b)

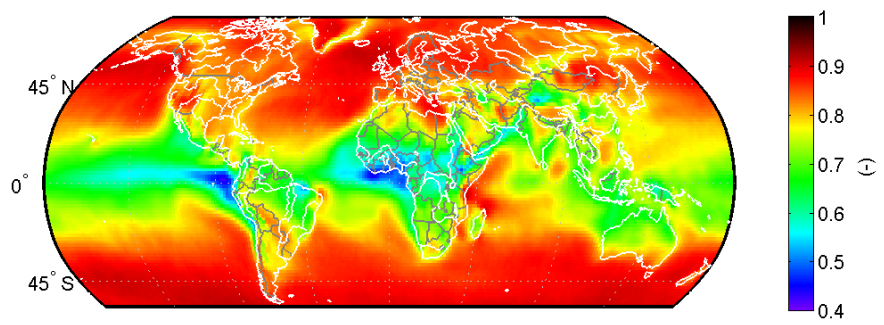

Fig. 11. Horizontal moisture flux shear factors as defined by Eqs. (7) and (8) averaged over 1999-2008 according to ERA-Interim reanalysis. (a) Zonal moisture flux shear factor, and (b) meridional moisture flux shear factor. The lower the value the more sheared the moisture flux.

a posteriori models had difficulties reproducing the results of RCM-tag for a case study in West Africa (Sect. 3.2). Improved versions of the a posteriori models relaxed some of the original assumptions and obtained significantly better results (Sects. 3.3 and 3.4). We concluded that the number of layers in the vertical and the mixing assumption after evaporation had the largest influence on the results (Sect. 3.4), especially due to the strong wind shear in West Africa (Figs. 1 and 10).

How the results of previous studies would have been (e.g. Dominguez et al., 2006; Dirmeyer and Brubaker, 2007; Bisselink and Dolman, 2008; van der Ent et al., 2010; Goessling and Reick, 2011; Bagley et al., 2012; Keys et al., 2012; Tuinenburg et al., 2012; Wei et al., 2012) when they had used "improved" moisture tracking models is very much case-dependent. Detailed analysis is beyond the scope of this study, but Goessling and Reick (2013), for example, showed that there are significant differences (mainly in the tropics) in continental precipitation recycling ratios between 2-D and 3-D tracking. However, the global pattern, as also shown by the 2-D tracking study of van der Ent et al. (2010) and 3-D tracking study of Bosilovich et al. (2002), remains very similar. For the study of Tuinenburg et al. (2012) we can conclude that their estimates of recycled moisture within the Ganges basin were on the conservative side. Releasing the parcels in the lowest layer was found to increase the Ganges basin recycling by only $5 \%$ (Tuinenburg, 2013). This result is in line with Fig. 11, where wind shear is not as significant in India as in West Africa.

In WAM-2layers and 3D-T (all runs) the vertical moisture transport was forced by the instantaneous vertical wind speeds at the time resolution of the forcing data. In reality, as well as in the atmospheric models used to generate the forcing data, the vertical mixing of moisture is driven by turbulence, which acts on timescales of minutes. In this case though, we could simply use the vertical velocities, as the resolution of the forcing model MM5 was high enough not to apply a subgrid scale convective scheme. However, when either of the a posteriori moisture tracking methods would be applied to other cases where the forcing data has a coarser resolution (e.g. 6-hourly, $1^{\circ} \times 1^{\circ}$ grid) another solution must be found to deal with the vertical transport. In the case of WAM-2layers, we think that the vertical transport could be parameterized or obtained from the water balance. In the case of 3D-T, it may be wise to apply an initial mixing somewhere in between the original well-mixed assumption (Eq. 2) and the low mixing assumption (Sect. 3.3.2). Unfortunately, this modeller's choice can only be tested when one has forcing model information such as in this study. Investigation of exactly which initial mixing assumption would be appropriate 
Table 3. Recommended suitability* of methods considering both accuracy and computation speed. The choice for a method also dependents on location of the region (see Fig. 11), size of the tracer source area and available computational power (see Table 1).

\begin{tabular}{lccccc}
\hline Method & $\begin{array}{c}\text { Historical or present } \\
\text { day studies }\end{array}$ & $\begin{array}{c}\text { Scenario studies } \\
\text { RCM-tag }\end{array}$ & $\begin{array}{c}\text { Detailed local scale } \\
\text { (up to 1000 km) }\end{array}$ & $\begin{array}{c}\text { Regional scale } \\
\text { (up to 5000 km) }\end{array}$ & $\begin{array}{c}\text { Global scale } \\
\text { WAM (1 layer) }\end{array}$ \\
3D-T (E_wellmixing- & ++ & ++ & ++ & + & - \\
P_wellmixing) & ++ & + & 0 & + & + \\
\hline WAM-2layers & ++ & + & + & + & + \\
3D-T-E_lowmixing- & ++ & + & + & + & + \\
P_wellmixing & ++ & + & ++ & + \\
3D-T-E_lowmixing- & & & & + \\
P_fromclouds & & & & + \\
\hline
\end{tabular}

* “++" = very well suited, "+" = well suited, "0" = neutrally suited, and "-" = not well suited

for which input data (due to Eq. 3) is beyond the scope of this paper.

The well-mixed assumption of precipitation (Eq. 4) was relaxed in the 3D-T-E_lowmixing-P_fromclouds run (see Sects. 3.3.3 and 3.4.3). However, we could only do this as we had cloud water content information from MM5. In many other cases this would not always be available and one would have to assume a certain degree of mixing. In practice, we think that a well-mixed situation for precipitation can be assumed and we also showed that it does not influence the results much. Another issue that we did not address is the mixing due to re-evaporation and condensation during a precipitation event. This issue is discussed in detail by Goessling and Reick (2013) who applied 3-D water vapour tracers in ECHAM6 on a $1.875^{\circ} \times 1.875^{\circ}$ grid, but they also leave this a modeller's choice. It can, however, be observed that their lower and upper boundaries for this type of mixing yield very similar results.

As a side note, we also showed the differences between the Eulerian approach taken by RCM-tag and WAM and the Lagrangian approach taken by 3D-T. The tagged precipitation patterns generated by RCM-tag and WAM are smoother than those generated by 3D-T due to the numerical mixing on the Eulerian grid that does not occur in the Lagrangian method. Given the current experiment, it is not possible to determine whether the Eulerian or Lagrangian approach is more suitable. However, it clearly shows that a Lagrangian method should release a sufficient amount of tracer parcels to produce reliable results, which unfortunately comes at the cost of computation time. The Eulerian methods, on the other hand, must not use too small time steps in order to avoid too much numerical dispersion, but is also not recommended as this obviously increases computation time (see also Table 1).

Based on our investigations we can provide recommendations on when and where to use which model (Table 3 ). We recommend the use of a posteriori models over RCM-tag for historical or near-real time studies as a posteriori models are more flexible in their input data (they can, for example, draw on existing climate model, reanalyses or observational data sets). For future scenarios, new climate model runs may be necessary anyway and RCM-tag would be suitable, but offline methods can of course handle this as well. Regarding the most suitable method for a certain spatial scale it is logical that a very accurate method as RCM-tag is recommended for local studies, whereas this would be computationally costly on larger scales. WAM is not recommended for the localscale studies, especially in the tropics, where the wind shear factor is low, meaning a highly sheared system (Eqs. 7 and 8 and Fig. 11). However, this model is very fast and flexible for the larger scales, especially in its updated form (WAM2layers), but it might be difficult to find an appropriate height to split the bottom and the top layer. When applied on the local scale in areas with prominent wind shear (Fig. 11), 3D-T is not very suitable either. However, this method works well on the large scale, or on the local scale in areas that do not suffer that much from wind shear. The "E_lowmixing" versions of 3D-T are generally recommended above the wellmixed assumptions for released parcels on smaller spatial scales, but when interested in large spatial (and temporal) scales this is not likely to have a big effect (see also Fig. 9). In conclusion, we hope that the findings of this paper will be beneficial to future atmospheric moisture tracking and moisture recycling studies, giving them a better handle on the suitability of the several methods around.

\section{Supplementary material related to this article is available online at http://www.hydrol-earth-syst-sci.net/ 17/4869/2013/hess-17-4869-2013-supplement.zip.}


Acknowledgements. R. J. van der Ent and H. H. G. Savenije did this work as part of the research program Division for Earth and Life Sciences (ALW), which is financed by the Netherlands Organization for Scientific Research (NWO). O. A. Tuinenburg did this work as part of the European Union (FP6) funded Integrated Project WATCH. H.-R. Knoche and H. Kunstmann did this work as part the GLOWA-Volta project and the WASCAL project. We thank Bart van den Hurk, Helge Goessling and one anonymous reviewer for their constructive comments.

Edited by: B. van den Hurk

\section{References}

Bagley, J. E., Desai, A. R., Dirmeyer, P. A., and Foley, J. A.: Effects of land cover change on moisture availability and potential crop yield in the world's breadbaskets, Environ. Res. Lett., 7, 014009, doi:10.1088/1748-9326/7/1/014009, 2012.

Benton, G. S.: The Role of the Atmosphere in the Hydrologic Cycle, Weatherwise, 2, 99-103, doi:10.1080/00431672.1949.9927025, 1949.

Bisselink, B. and Dolman, A. J.: Precipitation recycling: Moisture sources over Europe using ERA-40 data, J. Hydrometeorol., 9, 1073-1083, doi:10.1175/2008JHM962.1, 2008.

Bosilovich, M. G.: On the vertical distribution of local and remote sources of water for precipitation, Meteorol. Atmos. Phys., 80, 31-41, doi:10.1007/s007030200012, 2002.

Bosilovich, M. G. and Chern, J. D.: Simulation of water sources and precipitation recycling for the MacKenzie, Mississippi, and Amazon River basins, J. Hydrometeorol., 7, 312-329, doi:10.1175/JHM501.1, 2006.

Bosilovich, M. G. and Schubert, S. D.: Water vapor tracers as diagnostics of the regional hydrologic cycle, J. Hydrometeorol., 3, 149-165, doi:10.1175/15257541(2002)003<0149:WVTADO>2.0.CO;2, 2002.

Bosilovich, M. G., Sud, Y., Schubert, S. D., and Walker, G. K.: GEWEX CSE sources of precipitation using GCM water vapor tracers, GEWEX News, 12, 6-7, 2002.

Brubaker, K. L., Entekhabi, D., and Eagleson, P. S.: Estimation of continental precipitation recycling, J. Climate, 6, 1077-1089, doi:10.1175/1520-0442(1993)006<1077:EOCPR>2.0.CO;2, 1993.

Budyko, M. I.: Climate and Life, Academic Press, New York, 508 pp., 1974.

Burde, G. I. and Zangvil, A.: The estimation of regional precipitation recycling, Part I: Review of recycling models, J. Climate, 14, 2497-2508, doi:10.1175/15200442(2001)014<2497:TEORPR>2.0.CO;2, 2001a.

Burde, G. I. and Zangvil, A.: The estimation of regional precipitation recycling, Part II: A new recycling model, J. Climate, 14, 2509-2527, doi:10.1175/15200442(2001)014<2509:TEORPR>2.0.CO;2, $2001 \mathrm{~b}$.

Cook, K. H.: Generation of the African Easterly Jet and Its Role in Determining West African Precipitation, J. Climate, 12, 11651184, doi:10.1175/1520-0442(1999)012<1165:gotaej>2.0.co;2, 1999.
Dee, D. P., Uppala, S. M., Simmons, A. J., Berrisford, P., Poli, P., Kobayashi, S., Andrae, U., Balmaseda, M. A., Balsamo, G., Bauer, P., Bechtold, P., Beljaars, A. C. M., van de Berg, L., Bidlot, J., Bormann, N., Delsol, C., Dragani, R., Fuentes, M., Geer, A. J., Haimberger, L., Healy, S. B., Hersbach, H., Hòlm, E. V., Isaksen, L., Kållberg, P., Köhler, M., Matricardi, M., McNally, A. P., Monge-Sanz, B. M., Morcrette, J. J., Park, B. K., Peubey, C., de Rosnay, P., Tavolato, C., Thépaut, J. N., and Vitart, F.: The ERA-Interim reanalysis: Configuration and performance of the data assimilation system, Q. J. Roy. Meteorol. Soc., 137, 553597, doi:10.1002/qj.828, 2011.

Dirmeyer, P. A. and Brubaker, K. L.: Contrasting evaporative moisture sources during the drought of 1988 and the flood of 1993, J. Geophys. Res., 104, 19383-19397, doi:10.1029/1999JD900222, 1999.

Dirmeyer, P. A. and Brubaker, K. L.: Characterization of the global hydrologic cycle from a back-trajectory analysis of atmospheric water vapor, J. Hydrometeorol., 8, 20-37, doi:10.1175/JHM557.1, 2007.

Dominguez, F. and Kumar, P.: Precipitation recycling variability and ecoclimatological stability - A study using NARR Data, Part I: Central U.S. plains ecoregion, J. Climate, 21, 5165-5186, doi:10.1175/2008JCLI1756.1, 2008.

Dominguez, F., Kumar, P., Liang, X. Z., and Ting, M.: Impact of atmospheric moisture storage on precipitation recycling, J. Climate, 19, 1513-1530, doi:10.1175/JCLI3691.1, 2006.

Draxler, R. R. and Hess, G. D.: Description of the HYSPLIT_4 modeling system of trajectories, dispersion, and deposition, Austral. Meteorol. Mag., 47, 295-308, 1998.

Draxler, R. R. and Rolph, G. D.: HYSPLIT (HYbrid Single-Particle Lagrangian Integrated Trajectory) Model, http://ready.arl.noaa. gov/HYSPLIT.php, last access: 28 May 2013.

Durkee, J. D., Campbell, L., Berry, K., Jordan, D., Goodrich, G., Mahmood, R., and Foster, S.: A Synoptic Perspective of the Record 1-2 May 2010 Mid-South Heavy Precipitation Event, B. Am. Meteorol. Soc., 93, 611-620, doi:10.1175/bams-d-1100076.1, 2012

Eltahir, E. A. B. and Bras, R. L.: Precipitation recycling, Rev. Geophys., 34, 367-378, doi:10.1029/96RG01927, 1996.

Fitzmaurice, J.: A critical Analysis of Bulk Precipitation Recycling Models, Ph.D. thesis, Massachusetts Institute of Technology, Massachusetts, 2007.

Froehlich, K., Kralik, M., Papesch, W., Rank, D., Scheifinger, H., and Stichler, W.: Deuterium excess in precipitation of Alpine regions - Moisture recycling, Isotop. Environ. Health Stud., 44, 61-70, doi:10.1080/10256010801887208, 2008.

Gangoiti, G., Gómez-Domenech, I., Sáez de Cámara, E., Alonso, L., Navazo, M., Iza, J., García, J. A., Ilardia, J. L., and Millán, M. M.: Origin of the water vapor responsible for the European extreme rainfalls of August 2002: 2. A new methodology to evaluate evaporative moisture sources, applied to the August 11-13 central European rainfall episode, J. Geophys. Res., 116, D21103, doi:10.1029/2010jd015538, 2011.

Gimeno, L., Drumond, A., Nieto, R., Trigo, R. M., and Stohl, A.: On the origin of continental precipitation, Geophys. Res. Lett., 37, L13804, doi:10.1029/2010g1043712, 2010. 
Gimeno, L., Stohl, A., Trigo, R. M., Dominguez, F., Yoshimura, K., Yu, L., Drumond, A., Durán-Quesada, A. M., and Nieto, R.: Oceanic and Terrestrial Sources of Continental Precipitation, Rev. Geophys., 50, RG4003, doi:10.1029/2012RG000389, 2012.

Goessling, H. F. and Reick, C. H.: What do moisture recycling estimates tell us? Exploring the extreme case of nonevaporating continents, Hydrol. Earth Syst. Sci., 15, 3217-3235, doi:10.5194/hess-15-3217-2011, 2011.

Goessling, H. F. and Reick, C. H.: On the "well-mixed" assumption and numerical 2-D tracing of atmospheric moisture, Atmos. Chem. Phys., 13, 5567-5585, doi:10.5194/acp-13-55672013, 2013.

Grell, G. A., Dudhia, J., and Stauffer, D. R.: A description of the Fifth-Generation Penn State/NCAR mesoscale model (MM5), Tech. rep., http://www.mmm.ucar.edu/mm5/documents/ mm5-desc-doc.html, National Center for Atmospheric Research, Boulder, USA, 1995.

Henderson-Sellers, A., McGuffie, K., and Zhang, H.: Stable isotopes as validation tools for global climate model predictions of the impact of Amazonian deforestation, J. Climate, 15, 26642677, 2002.

Hossain, F., Jeyachandran, I., and Pielke Sr., R. A.: Have Large Dams Altered Extreme Precipitation Patterns, Eos Trans. AGU, 90, doi:10.1029/2009EO480001, 2009.

Jódar, J., Carrera, J., and Cruz, A.: Irrigation enhances precipitation at the mountains downwind, Hydrol. Earth Syst. Sci., 14, 2003 2010, doi:10.5194/hess-14-2003-2010, 2010.

Joussaume, S., Sadourny, R., and Vignal, C.: Origin of precipitating water in a numerical simulation of the July climate, Ocean-Air Interact., 1, 43-56, 1986.

Keys, P. W., van der Ent, R. J., Gordon, L. J., Hoff, H., Nikoli, R., and Savenije, H. H. G.: Analyzing precipitationsheds to understand the vulnerability of rainfall dependent regions, Biogeosciences, 9, 733-746, doi:10.5194/bg-9-733-2012, 2012.

Knoche, H. R. and Kunstmann, H.: Tracking atmospheric water pathways by direct evaporation tagging: A case study for West Africa, J. Geophys. Res., accepted, doi:10.1002/2013JD019976 2013.

Koster, R., Jouzel, J., Suozzo, R., Russell, G., Broecker, W., Rind, D., and Eagleson, P.: Global sources of local precipitation as determined by the NASA/GISS GCM, Geophys. Res. Lett., 13, 121-124, doi:10.1029/GL013i002p00121, 1986.

Koster, R. D., Dirmeyer, P. A., Guo, Z., Bonan, G., Chan, E., Cox, P., Gordon, C. T., Kanae, S., Kowalczyk, E., Lawrence, D., Liu, P., Lu, C. H., Malyshev, S., McAvaney, B., Mitchell, K., Mocko, D., Oki, T., Oleson, K., Pitman, A., Sud, Y. C., Taylor, C. M., Verseghy, D., Vasic, R., Xue, Y., and Yamada, T.: Regions of strong coupling between soil moisture and precipitation, Science, 305, 1138-1140, doi:10.1126/science.1100217, 2004.

Kunstmann, H. and Jung, G.: Influence of soil-moisture and land use change on precipitation in the Volta Basin of West Africa, Int. J. River Basin Manage., 5, 9-16, doi:10.1080/15715124.2007.9635301, 2007.

Lettau, H., Lettau, K., and Molion, L. C.: Amazonia's hydrological cycle and the role of atmospheric recycling in assessing deforestation effects, Mon. Weather Rev., 107, 227-238, doi:10.1175/1520-0493(1979)107<0227:AHCATR>2.0.CO;2, 1979.
Lintner, B. R., Gentine, P., Findell, K. L., D’Andrea, F. D., Sobel, A. H., and Salvucci, G. D.: An Idealized Prototype for LargeScale Land-Atmosphere Coupling, J. Climate, 26, 2379-2389, doi:10.1175/JCLI-D-11-00561.1, 2013.

Liu, Z., Tian, L., Yao, T., and Yu, W.: Seasonal deuterium excess in Nagqu precipitation: Influence of moisture transport and recycling in the middle of Tibetan Plateau, Environ. Geol., 55, 15011506, doi:10.1007/s00254-007-1100-4, 2008.

McDonald, J. E.: The evaporation precipitation fallacy, Weather, 17, 168-179, doi:10.1002/j.1477-8696.1962.tb02682.x, 1962.

Molion, L. C. B.: A climatonomic study of the energy and moisture fluxes of the Amazon basin with consideration on deforestation, Ph.D. thesis, University of Wisconsin, 1975.

Nieto, R., Gimeno, L., and Trigo, R. M.: A Lagrangian identification of major sources of Sahel moisture, Geophys. Res. Lett., 33, L18707, doi:10.1029/2006GL027232, 2006.

Njitchoua, R., Sigha-Nkamdjou, L., Dever, L., Marlin, C., Sighomnou, D., and Nia, P.: Variations of the stable isotopic compositions of rainfall events from the Cameroon rain forest, Central Africa, J. Hydrol., 223, 17-26, doi:10.1016/S00221694(99)00087-6, 1999.

Pang, Hongxi, He, Yuanqing, Zhang, Zhonglin, Lu, Aigang, and Gu, Juan: The origin of summer monsoon rainfall at New Delhi by deuterium excess, Hydrol. Earth Syst. Sci., 8, 115-118, doi:10.5194/hess-8-115-2004, 2004.

Pidwirny, M.: Global Scale Circulation of the Atmosphere, in: Fundamentals of Physics Geography, PhysicalGeography.net, 2nd Edn., http://www.physicalgeography.net/fundamentals/7p. html (last access: 28 May 2013), 2006.

Risi, C., Noone, D., Frankenberg, C., and Worden, J.: The role of continental recycling in intra-seasonal variations of continental moisture as deduced from model simulations and water vapor isotopic measurements, Water Resour. Res., 49, 4136-4156, doi:10.1002/wrcr.20312, 2013.

Salati, E., Dall'olio, A., Matsui, E., and Gat, J. R.: Recycling of water in the Amazon Basin: an isotopic study, Water Resour. Res., 15, 1250-1258, doi:10.1029/WR015i005p01250, 1979.

Savenije, H. H. G.: New definitions for moisture recycling and the relationship with land-use changes in the Sahel, J. Hydrol., 167, 57-78, doi:10.1016/0022-1694(94)02632-L, 1995a.

Savenije, H. H. G.: Does moisture feedback affect rainfall significantly?, Phys. Chem. Earth, 20, 507-513, doi:10.1016/S00791946(96)00014-6, 1995 b.

Schaefli, B., van der Ent, R. J., Woods, R., and Savenije, H. H. G.: An analytical model for soil-atmosphere feedback, Hydrol. Earth Syst. Sci., 16, 1863-1878, doi:10.5194/hess-16-18632012, 2012.

Schär, C., Lüthi, D., Beyerle, U., and Heise, E.: The soilprecipitation feedback: A process study with a regional climate model, J. Climate, 12, 722-741, doi:10.1175/15200442(1999)012<0722:TSPFAP>2.0.CO;2, 1999.

Sodemann, H., Schwierz, C., and Wernli, H.: Interannual variability of Greenland winter precipitation sources: Lagrangian moisture diagnostic and North Atlantic Oscillation influence, J. Geophys. Res., 113, D03107, doi:10.1029/2007jd008503, 2008.

Sodemann, H., Wernli, H., and Schwierz, C.: Sources of water vapour contributing to the Elbe flood in August 2002 - A tagging study in a mesoscale model, Q. J. Roy. Meteorol. Soc., 135, 205-223, doi:10.1002/qj.374, 2009. 
Spracklen, D. V., Arnold, S. R., and Taylor, C. M.: Observations of increased tropical rainfall preceded by air passage over forests, Nature, 489, 282-285, doi:10.1038/nature11390, 2012.

Stohl, A. and James, P.: A Lagrangian analysis of the atmospheric branch of the global water cycle, Part II: Moisture transports between earth's ocean basins and river catchments, J. Hydrometeorol., 6, 961-984, doi:10.1175/JHM470.1, 2005.

Stohl, A., Forster, C., Frank, A., Seibert, P., and Wotawa, G.: Technical note: The Lagrangian particle dispersion model FLEXPART version 6.2, Atmos. Chem. Phys., 5, 2461-2474, doi:10.5194/acp-5-2461-2005, 2005.

Taylor, C. M., Harris, P. P., and Parker, D. J.: Impact of soil moisture on the development of a Sahelian mesoscale convective system: a case-study from the AMMA Special Observing Period, Q. J. Roy. Meteorol. Soc., 136, 456-470, doi:10.1002/qj.465, 2010.

Tian, L., Yao, T., MacClune, K., White, J. W. C., Schilla, A., Vaughn, B., Vachon, R., and Ichiyanagi, K.: Stable isotopic variations in west China: A consideration of moisture sources, J. Geophys. Res., 112, D10112, doi:10.1029/2006JD007718, 2007.

Trenberth, K. E.: Atmospheric moisture recycling: Role of advection and local evaporation, J. Climate, 12, 1368-1381, doi:10.1175/1520-0442(1999)012<1368:AMRROA>2.0.CO;2, 1999.

Tuinenburg, O. A.: Atmospheric Effects of Irrigation in Monsoon Climate: The Indian Subcontinent, Ph.D. thesis, Wageningen University, 2013.

Tuinenburg, O. A., Hutjes, R. W. A., and Kabat, P.: The fate of evaporated water from the Ganges basin, J. Geophys. Res., 117, D01107, doi:10.1029/2011jd016221, 2012. van den Hurk, B. J. J. M. and van Meijgaard, E.: Diagnosing Land-Atmosphere Interaction from a Regional Climate Model Simulation over West Africa, J. Hydrometeorol., 11, 467-481, doi:10.1175/2009jhm1173.1, 2009.

van der Ent, R. J.: Interactive comment on "Atmospheric water vapour tracers and the significance of the vertical dimension" by H. F. Goessling and C. H. Reick, Atmos. Chem. Phys. Discuss., 12, C10180-C10188, 2012.

van der Ent, R. J. and Savenije, H. H. G.: Length and time scales of atmospheric moisture recycling, Atmos. Chem. Phys., 11, 18531863, doi:10.5194/acp-11-1853-2011, 2011.

van der Ent, R. J., Savenije, H. H. G., Schaefli, B., and Steele-Dunne, S. C.: Origin and fate of atmospheric moisture over continents, Water Resour. Res., 46, W09525, doi:10.1029/2010WR009127, 2010.

van der Ent, R. J., Coenders-Gerrits, A. M. J., Nikoli, R., and Savenije, H. H. G.: The importance of proper hydrology in the forest cover-water yield debate: commentary on Ellison et al. (2012) Global Change Biology, 18, 806-820, Global Change Biol., 18, 2677-2680, doi:10.1111/j.1365-2486.2012.02703.x, 2012.

Wei, J., Dirmeyer, P. A., Wisser, D., Bosilovich, M. G., and Mocko, D. M.: Where does the irrigation water go? An estimate of the contribution of irrigation to precipitation using MERRA, J. Hydrometeorol., 14, 275-289, doi:10.1175/jhm-d-12-079.1, 2012.

Yoshimura, K., Oki, T., Ohte, N., and Kanae, S.: Colored moisture analysis estimates of variations in 1998 Asian monsoon water sources, J. Meteorol. Soc. Jpn., 82, 1315-1329, doi:10.2151/jmsj.2004.1315, 2004. 